\title{
Advancements in postpartum hemorrhage care (APPHC): Overview of portfolio development and research studies in Malawi
}

Breakthrough RESEARCH

USAID's Health Evaluation and Applied Research Development

Follow this and additional works at: https://knowledgecommons.popcouncil.org/departments_sbsr-rh

Part of the Health Communication Commons, and the Public Health Commons How does access to this work benefit you? Let us know!

\section{Recommended Citation}

Breakthrough RESEARCH and USAID's Health Evaluation and Applied Research Development. 2021. "Advancements in postpartum hemorrhage care (APPHC): Overview of portfolio development and research studies in Malawi," APPHC Programmatic Research Brief. Washington, DC: Breakthrough RESEARCH and URC. 


\section{Advancements in Postpartum Hemorrhage Care (APPHC): Overview of Portfolio Development and Research Studies in Malawi}

The maternal mortality ratio in Malawi is one of the highest in sub-Saharan Africa, at 439 per 100,000 live births, of which an estimated $25 \%$ is due to postpartum hemorrhage (PPH)., ${ }^{1,2}$ Despite an increase in institutional deliveries, up from 51\% in 1992 to $91 \%$ in $2015,{ }^{3}$ many preventable maternal deaths continue to occur at facilities. Additionally, only $42 \%$ of women receive a check-up within 48 hours of delivery. Facilities in Malawi face persistent challenges including limited human resources, provider vulnerabilities, weak infrastructure, commodity availability, and lack of functioning referral systems and quality improvement efforts. In light of these challenges, there is a need to develop and implement effective strategies and interventions to advance $\mathrm{PPH}$ prevention and treatment in Malawi.

In response to this need, and as part of ongoing efforts to accelerate reductions in maternal deaths, U. S. Agency for International Development (USAID) is supporting a one-time catalytic investment in Malawi and Madagascar collectively referred to as Advancements in Postpartum Hemorrhage Care (APPHC). The APPHC Partnership is led by Breakthrough RESEARCH and the Health Evaluation and Applied Research Development (HEARD) Projects. A description of the APPHC Partnership Approach is also available.

This brief outlines the portfolio of research activities underway in Malawi. A similar brief describes the Madagascar portfolio.

\section{APPHC Priority Development}

The priority development process was iterative and consultative and resulted in a demand among local stakeholders

\begin{abstract}
for research findings that inform action and a research portfolio that is responsive to that demand.
\end{abstract}

PPH prevention and treatment relates to a range of determinants and a vast number of actions that can be studied for practical improvement in Malawi. Our starting point considered two constraints (time and resources) and opportunities to inform positive change through the generation of actionable, timely, and relevant evidence. Fortunately, APPHC had a built-in starting point by way of a major health system bilateral project funded by USAID: Organized Network of Services for Everyone's (ONSE) Health Activity in Malawi, led by Management Sciences for Health. This large implementation investment and existing collaboration with the Ministry of Health \& Population $(\mathrm{MoH})$ and other key decision-makers created a platform ripe for embedding within and linking to for the APPHC activities. APPHC seeks to inform the MoH and ONSE strategies and activities, future USAID investments, and also respond to opportunities and needs expressed by additional key decision-makers and stakeholders in country.

The goal of ONSE's Health Activity, which began in 2016, is to improve maternal, newborn, and child survival and well-being, with specific objectives to:
- Increase access to priority health services
- Improve the quality of priority health services
- Strengthen the performance of health systems
- Increase the demand for priority health services

The majority of research activities (particularly on provider behavioral and non-behavioral determinants) are taking place in ONSE-supported districts and build on their existing workplan for essential maternal and newborn health care.

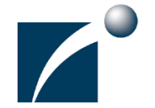

Breakthrough RESEARCH 


\section{Research Domains Identified During Prioritization at Country Level}

The APPHC start-up phase consisted of a desk review, stakeholder consultations, and workshops. From these, a number of key implementation science themes and research domains were synthesized (see table).

\section{APPHC Portfolio of Activities}

The HEARD and Breakthrough RESEARCH projects are designed to bring deep implementation research (IR) and social and behavior change global research expertise and experience that produce high quality evidence and strengthen institutional capacities in these fields. A number of institutions in Malawi contributed to the co-design ${ }^{a}$ of research activities. The APPHC Partnership bolsters research efforts by prompting the technical and ethical review of research protocols by global and local institutional review boards and subject matter experts. The portfolio of activities, which is co-led by HEARD, Breakthrough RESEARCH, and Malawi-based partners, includes two activity groups:

${ }^{a} \mathrm{MoH}$ Reproductive Health Directorate, $\mathrm{MoH}$ Research Division, University of Malawi-College of Medicine, Kamuzu College of Nursing (KCN), ideas42, VillageReach implementation research studies and real-time evidence/data use and dissemination. The activities build on previous investments and knowledge and consist of a multi-dimensional approach to generate and test solutions and to advance implementation of successful strategies.

\section{APPHC Malawi portfolio}

\section{Implementation research activities}

- Provider support implementation research study: This mixed methods study aims to understand PPH knowledge, practices and the levels of burnout and stress that prevents optimum provision of care in busy maternity units including poor management of $\mathrm{PPH}$. It includes two separate interventions:

- Reducing provider vulnerabilities ${ }^{\mathrm{b}}$ : This piece aims to examine intervention strategies for addressing burnout, poor motivation, and poor adherence to national guidelines for prevention and management of PPH. The approach also aims to strengthen partnerships between providers and women and her companion, communication, inter-professional collaboration, and woman-centered maternal care (WCMC).

- Enhancing health provider mentorship ${ }^{c}$ : This component of the study aims to examine an approach to strengthening clinical mentorship for improving the

\footnotetext{
${ }^{b}$ Implementing partner: $\mathrm{KCN}$

Implementing partner: PRONTO, KCN
}

\section{KEY IMPLEMENTATION SCIENCE THEMES AND RESEARCH DOMAINS SYNTHESIZED FROM APPHC START-UP PHASE}

\section{Key Implementation Science Themes}

Key behavioral and non-behavioral determinants affecting health providers' behaviors and practices including provider vulnerabilities

Key models and approaches related to service delivery

Key opportunities for analysis of existing data and strengthening processes for data use

Case studies on Innovation/Adaptation

\section{Research Domains}

Provider motivation, expectation, ability and opportunity

Provider vulnerabilities including stressors and causes of burnout

Provider norms and values

Intervention strategies to improve provider behavior

Teamwork and mentorship strategies

Human resources management recruitment and deployment, retention and support

Transport and referral system/community mobilization

Emergency response models

Mentorship/training/support

Supply chain/ commodities/equipment

Maternal death surveillance and response (MDSR) analysis

Near miss audits

Blood transfusion supply

Maternity waiting homes

Non-pneumatic anti-shock garments (NASG)

Emergency support call-in center 
management of PPH at facility levels by introducing and testing a simulation-based mentorship approach. In addition to strengthening individual provider skills and knowledge, the approach aims to strengthen teamwork, communication, inter-professional collaboration, and WCMC.

- Integrating near-miss reviews in the MDSR process ${ }^{\mathrm{d}}$ : As formative data demonstrated that properly documenting cases of saved maternal lives was a motivator to health care workers and led to improved reporting of PPH-related obstetric emergencies at the local, regional and national levels, this study evaluates the integration of maternal near-miss case reviews into the pre-existing MDSR system to improve the identification and management of PPH.

\section{Real-time evidence/data use and dissemination}

In addition to the implementation research activities, the partnership is conducting a number of activities to collect, analyze and disseminate evidence.

- Strategic communication and dissemination: Through strategic communications and knowledge management tools, APPHC informs and is informed by national, regional, and global technical networks to accelerate learning and use of evidence to improve PPH prevention and treatment.

- Ongoing data analysis, synthesis, and interpretation ${ }^{\mathrm{e}}$ In service to ONSE and the $\mathrm{MoH}, \mathrm{APPHC}$ is supporting analysis, synthesis, and interpretation of existing data to inform decision-making around PPH and essential maternity services.

- Case studies: These activities draw upon and link across other portfolio activities by exploring opportunities to do a rapid, deeper analysis of context and interventions aimed at the prevention and treatment of $\mathrm{PPH}$ to strengthen understanding of services, supplies, provider readiness, and system resilience in the current context.

- Examining the utility of a health hotline for PPH referralf: Qualitative interviews and secondary analysis of calls to the national health hotline will detail how health providers respond to women experiencing obstetric emergencies, including PPH, as well as identify the concerns and characteristics of these callers to improve the effectiveness of the hotline and responding providers' ability to provide actionable, timely health advice in cases of obstetric emergency.

- Reviewing bottlenecks related to use and maintenance of the NASG': To better understand the use of NASG, qualitative interviews with a selection of providers working in maternity units are being conducted and analyzed. Some quantitative data will also be incorporated from the provider interviews regarding knowledge of use and actual use of the NASG.

- Use of maternity waiting homes $(\mathrm{MWH})^{\mathrm{h}}$ : To assess the use of MWHs as they relate to PPH prevention and treatment, a small case study incorporates qualitative interviews describing women and provider perceptions of MWH use and whether it is feasible for women at risk of $\mathrm{PPH}$ to remain in the $\mathrm{MWH}$ after discharge and before they return home.

- Understanding availability and access to bloodi: This case study on blood banking will elucidate the supply side gaps and challenges in blood banking, storage, and distribution processes as well as the demand side requests and uses of blood. This information is critical to implement actions to minimize blood shortages particularly for life-threatening obstetric hemorrhage.

- Process documentation: The APPHC team is strategically documenting the contextual, systemic and behavioral factors that affect the implementation and success of this effort. The team is engaging with local collaborators to explore opportunities and capture interactions and processes-particularly in light of COVID-19-during the APPHC activity period.

\section{Influencing Change}

To date, the APPHC Partnership has fostered high-level discussions in which policy is being informed through learning across USAID investments. Evidence generation activities are currently underway and the APPHC Partnership looks forward to providing recommendations to inform more effective programming among current USAID projects (e.g., ONSE), the MoH and beyond. The APPHC Partnership is always considering new ways to link and leverage other global maternal health efforts, and hopes to inform the next critical set of implementation science and research priorities.

\footnotetext{
${ }^{\mathrm{h}}$ Implementing partner: $\mathrm{KCN}$

Implementing partner: Malawi College of Medicine, Malawi Blood Transfu sion Service
}

\footnotetext{
d Implementing partner: Malawi College of Medicine

e Implementing partner: Malawi College of Medicine

f Implementing partner: VillageReach

s Implementing partner: KCN
} 


\section{References}

${ }^{1}$ Geubbels E. 2006. "Epidemiology of maternal mortality in Malawi," Malawi Medical Journal 18: 206-225.

${ }^{2}$ Kongnyuy, E. J., G. Mlava, and N. van den Broek. 2009. "Facility-based maternal death review in three districts in the central region of Malawi: an analysis of causes and characteristics of maternal deaths," Womens Health Issues 19(1): 14-20.

${ }^{3}$ National Statistical Office (NSO) [Malawi] and ICF. 2017. Malawi Demographic and Health Survey 2015-16. Zomba, Malawi, and Rockville, Maryland, USA. NSO and ICF.

This work is part of the Advancing Postpartum Hemorrhage Care (APPHC) partnership supported by USAID and led by the Breakthrough RESEARCH Project and the Health Evaluation and Applied Research Development (HEARD) Project. The APPHC partnership generates and tests solutions to address key implementation barriers for PPH prevention and treatment and contributes to the effective implementation of interventions, strategies, and innovations for PPH in Madagascar and Malawi.

https://www.respectfulcareresources.com/apphc

\section{Suggested citation:}

Breakthrough RESEARCH and USAID's Health Evaluation and Applied Research Development. 2021. "Advancements in postpartum hemorrhage care (APPHC): Overview of portfolio development and research studies in Malawi," APPHC Programmatic Research Brief. Washington DC: Population Council and URC.

\section{Breakthrough RESEARCH}

\section{Population Council}

4301 Connecticut Ave., NW

Suite 280

Washington, DC 20008

+12022379400

breakthroughactionandresearch.org

BreakthroughResearch@popcouncil.org
USAID's Health Evaluation and Applied Research Development

URC

5404 Wisconsin Ave Suite 800

Chevy Chase, MD 20815

www.heardproject.org

heard@urc-chs.com
This document is made possible by the generous support of the American people through the United States Agency for International Development (USAID) under cooperative agreements Breakthrough RESEARCH (AID-OAA-A-17-00018) and USAID's Health Evaluation and Applied Research Development Project (HEARD) (AID-OAA-A-17-00002). The contents of this document are the sole responsibility of Breakthrough RESEARCH, Population Council, and University Research Co., LLC and do not necessarily reflect the views of USAID or the United States Government.

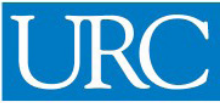

'S HEALTH EVALUATION AND APPLIED RESEARCH DEVELOPMENT (HEARD) PROJECT

USAID's Health Evaluation and Applied Research Development (HEARD) project leverages a global partnership of more than 30 institutions to generate, synthesize, and use evidence to improve the implementation of policies and programs related to USAID priority areas, and crucial for improving health and development in low and middle-income countries.

\section{- POpUlation COUNCIL}

Ideas. Evidence. Impact.

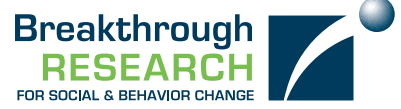

FOR SOCIAL \& BEHAVIOR CHAN
Breakthrough RESEARCH catalyzes SBC by conducting state-of-the-art research and evaluation and promoting evidence-based solutions to improve health and development programs around the world. Breakthrough RESEARCH is a consortium led by the Population Council in partnership with Avenir Health, ideas42, Institute for Reproductive Health at Georgetown University, Population Reference Bureau, and Tulane University. 